\title{
Geographic Tongue
}

Emili Masferrer, M.D.

Anna Jucgla, M.D.

Hospital Universitari de Bellvitge

Barcelona, Spain

emilimasferreriniubo@gmail.com

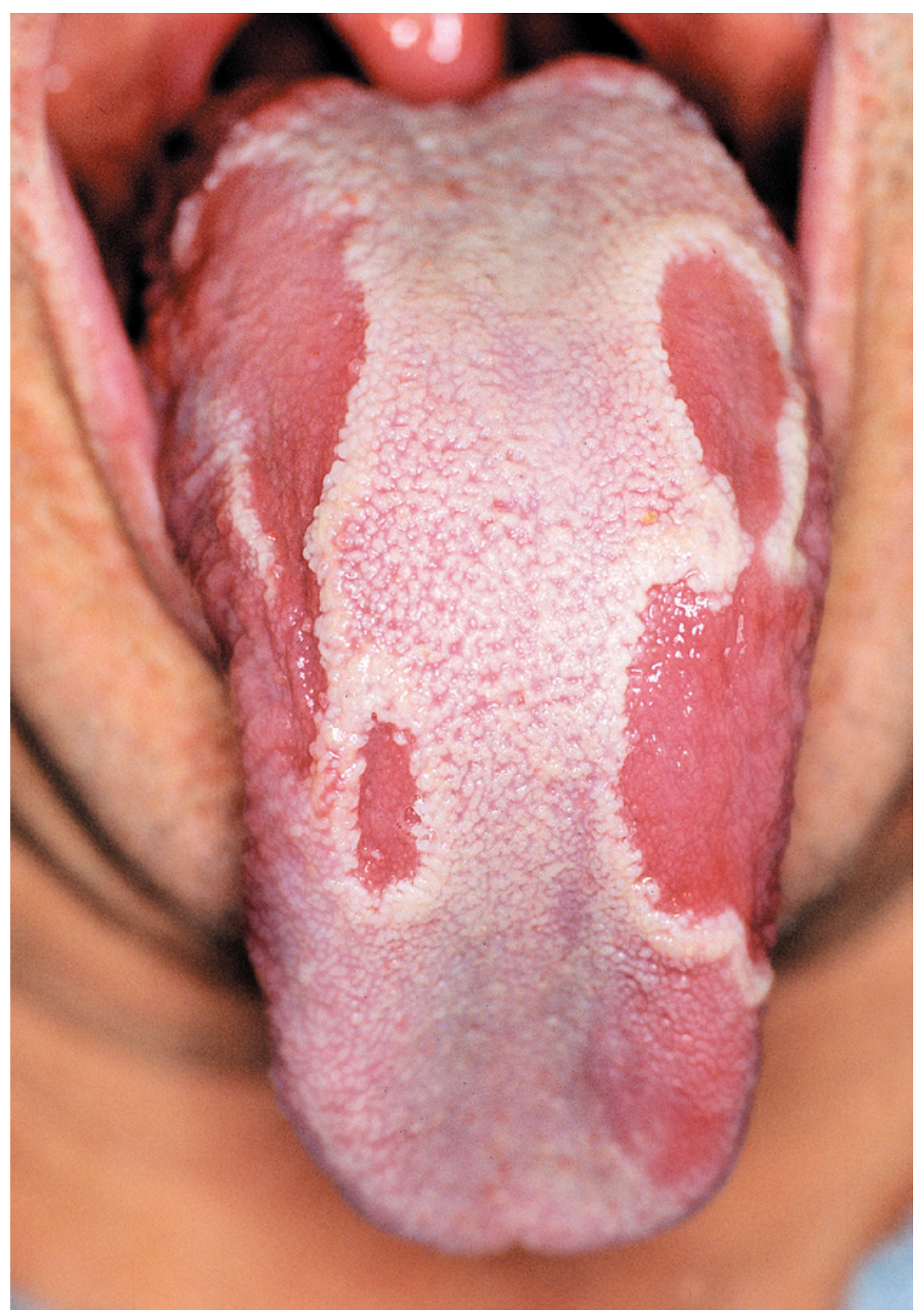

61-YEAR-OLD MAN WAS REFERRED FOR TREATMENT OF PAINLESS WHITE LESIONS ON HIS TONGUE THAT had appeared 1 month earlier. He had been treated with topical and systemic antifungal drugs for presumed oral candidiasis, but the lesions remained unchanged. The patient reported that a similar episode 1 year earlier had resolved spontaneously. Lingual examination revealed multiple erythematous patches with an annular, welldemarcated white border. A diagnosis of geographic tongue was made. Geographic tongue (benign migratory glossitis) is a benign inflammatory condition that affects approximately $2 \%$ of the world's population. The classic manifestation is a maplike distribution of erythema caused by atrophy of the filiform papillae of the tongue, surrounded by a white hyperkeratotic rim. The lesions typically resolve spontaneously without sequelae but can develop quickly in other areas of the tongue.

Copyright (C) 2009 Massachusetts Medical Society. 